\title{
The Status and Identification of Improvements of Sustainable Hazardous Waste Minimization in a Chemical Company in Krugersdorp
}

\author{
Shadung John Moja $^{1} \&$ Spiwe Chimutashu ${ }^{1}$ \\ ${ }^{1}$ Department of Environmental Sciences, University of South Africa, Florida Campus, Roodepoort, South Africa \\ Correspondence: Shadung John Moja, Department of Environmental Sciences, University of South Africa, Florida \\ Campus, Roodepoort, South Africa. Tel: 27-11-4713-878. E-mail: mojasj@unisa.ac.za; shadung@yahoo.com
}

Received: August 25, 2013 Accepted: September 22, 2013 Online Published: September 15, 2014

doi:10.5539/jas.v6n10p9 URL: http://dx.doi.org/10.5539/jas.v6n10p9

\begin{abstract}
This study was necessary because, hazardous waste presents immediate or long-term risks to humans, animals, plants or the environment and it requires special handling in terms of detoxification or safe disposal. The general public associates chemical industries with problems that include waste disposal, pollution, disease danger, depletion of natural resources, and landfill. Chemical industries have developed different initiatives, with varying levels of success or failure, to address the problem of hazardous waste minimization. Waste minimization usually requires knowledge of the production process, cradle to grave analysis (the tracking of materials from their extraction to their return to earth) and detailed knowledge of the composition of the waste.

A detailed literature review was undertaken in order to obtain in-depth knowledge of waste minimization concepts and aspects. Legislation concerning waste minimization and management was also discussed. Information gaps and opportunities for improvements of chemical industries' waste minimization strategies were identified from this theoretical study. A questionnaire survey methodology was used in order to systematically identify the solution to this problem. Purposive sampling was used to select the required respondents that were working directly with hazardous waste at the company under study. Inferential and descriptive statistics were used to analyse the data obtained from the questionnaires. About $80.0 \%$ of the respondents constituted of mature adults and middle aged employees that is between 35-45 and 18-35 age groups, respectively. About 95.0\% of the respondents had at least reached high school. From the results over $60.0 \%$ of the respondents also highlighted the importance of awareness and training programmes in order to achieve sustainable hazardous waste minimization in manufacturing companies. Almost $70.0 \%$ of the respondents identified opportunities of improvements on issues related to product life cycle and processes.
\end{abstract}

Keywords: hazardous waste, waste management hierarchy, chemical industry, end of pipe, cradle to cradle, cradle to grave, product life cycle, sustainability

\section{Introduction}

Worldwide, the United Nations Environmental Programme (UNEP) estimated that more than 400 million tonnes of hazardous wastes are produced universally each year, mostly by industrialized countries (Fehr \& Schmit, 1999). Waste management issues are global concerns. Worldwide, a number of initiatives have been undertaken to ensure effective waste management. However, chemical industries are still faced with challenges to sustain the waste management programmes due to various factors. In 1992, the United Nations Conference on Environment and Development established an agenda (Agenda 21) for world action on the environment and increased international efforts towards sustainable development. Chapter 20 of Agenda 21 identifies the major programme areas related to the environmentally sound management of hazardous wastes, including preventing and minimizing of hazardous wastes (Carroll-Foster, 1993).

According to Jennings (2010), unsustainable linear consumption patterns result in the majority of our extracted and refined resources being used once and then discarded in landfill sites globally. Governmental effort alone is not enough to minimize hazardous waste, private organizations also have a role to play. There is need for every responsible stakeholder to cooperate. The pre-existence of a culture within an organization would have a basic 
influence on any formal management system. The culture of individual organizations, sites or even departments can affect how a system is used (Sheldon \& Yoxon, 2006).

Most chemical organizations have well established waste management procedures and strategies. However, the lack of sustainability inhibits the organizations to effectively and continuously manage their waste. The importance of the product life cycle or cradle to grave knowledge on hazardous waste minimization has been highlighted. Other researchers have suggested that the implementation of the advancement of cradle to grave also known as cradle to cradle is the ultimate solution. Based on literature reviewed, there was significant information which suggests that many institutions are still struggling with the basic cradle to grave management in Africa. According to DEA (2010), cradle to cradle management ensures that once a product reaches the end of its life span, its component parts are recovered, reused or recycled, thereby becoming inputs for new products and materials.

In the literature review, the waste hierarchy was identified as the main pillar of waste management. The Waste hierarchy ranks waste management options according to their relative environmental benefits (Hatlar, 2009). In South Africa, the waste hierarchy is a systematic and hierarchical approach to integrated waste management. The waste hierarchy system describes waste management according to waste avoidance, reduction, reuse, recycling, recovery, treatment and, as a last resort, the safe disposal of waste (DEA, 2010). This study focused on the second stage of the waste hierarchy, that is, waste minimization or reduction.

Knowledge of the life cycle stages of production (cradle to grave) was also identified to be crucial, during literature review. There was also a highlight on the encroaching cradle to cradle approach, which is an advancement of cradle to grave approach. One challenge this study identified was the need for African countries to advance from cradle to grave and move to the advanced cradle to cradle, due to lack of advanced technology. The objective of the research was to assist chemical industries in achieving hazardous waste minimization. Though the results in the study are important they could therefore be biased to the nature of business used as a case study, which is a paint manufacturing company. The likert-scaling in the questionnaire also posed validity challenges since it failed to measure the true attitudes of respondents. Also, it is not unlikely that peoples' answers will be influences by previous questions, or will heavily concentrate on one response side (agree/disagree).

This study investigated ways of hazardous waste minimization and to find methods of practical implementation of sustainable hazardous waste management in the chemical industry. The fundamental purpose of this study was to find ways of economically reducing volume of waste during production, by means of different processes, or uses, or 'clean' technology implementation. Successful waste minimization can improve production efficiency, profits, good neighbor image, product quality and environmental performance.

\section{Materials and Methods}

In order to establish a theoretical framework on sustainable implementation of hazardous waste minimization in chemical industries, detailed literature was reviewed. Various secondary data was analysed to obtain terms and concepts, legislation, gaps and opportunities related to the study.

The study was conducted at a paint and coatings manufacturing company based in Krugersdorp. Its activities entails paint preparation, mixing, storage and distribution. Its main processes includes receiving raw material, loading, premixing or dispersion, lab testing, let down (viscosity adjustment or tinting) filling, labeling, palletizing, transporting, checking and storage of finished goods.

There were two main divisions at this chemical company which included the manufacturing and nonmanufacturing departments. At the time of the study, there were eight (8) manufacturing plants at the company; the plants included Industrial Water Based, Polycell, Enamel, Resin, Emulsion, Water plant, Warehouse and Raw Material Store. There were various Non-manufacturing departments, but for the purpose of the study only three (3) departments were selected.

The target group of the study was employees working with hazardous waste from all product life cycle stages and at different management levels that is shop floor, middle and senior management levels. A pilot study was conducted on ten selected respondents coming from both the manufacturing and non-manufacturing departments dealing with hazardous waste that is, Buying and Expediting department, Safety, Health Environment Risk Quality (SHERQ) department and Factory Technical department.

The questions in the questionnaire were linked to the objectives of the study. Questions included demographics, problems preventing effective waste minimization waste types, product life cycle and processes. Questionnaires were distributed using purposive sampling technique within targeted departments. Purposive sampling was used in order to choose information rich cases. 
A total of 89 people were invited to participate in the actual study. Ten (10) participants from the eight (8) manufacturing departments and three (3) participants each from the three (3) non-manufacturing departments were issued with the questionnaires.

\section{Results and Discussion}

The data was analysed using inferential statistics and descriptive statistics. Descriptive statistics is the term given to the analysis of data that helps describe, shows or summarizes data in a meaningful way such that, for example, patterns might emerge from the data (Laerd, 2013). In this paper, graphs and a table were used to outline data. Inferential statistics is the technique that allows us to use these samples to make generalizations about the populations from which the samples have been drawn. It is, therefore, important that the sample accurately represents the population. Binominal test was used for inferential statistics in this paper (Laerd, 2013).

Descriptive statistics was used to analyse the demographic features of the paper. Figure 1, shows that the highest level of education that the respondents reached in the departments selected was mostly the high school level. These findings may be indicative of highest level of shop floor workers in the manufacturing plants. The relatively low level of the number of primary education level was very encouraging. Most respondents had basic education and level of education might have had an effect on the level of understanding of hazardous waste management strategies and purpose.

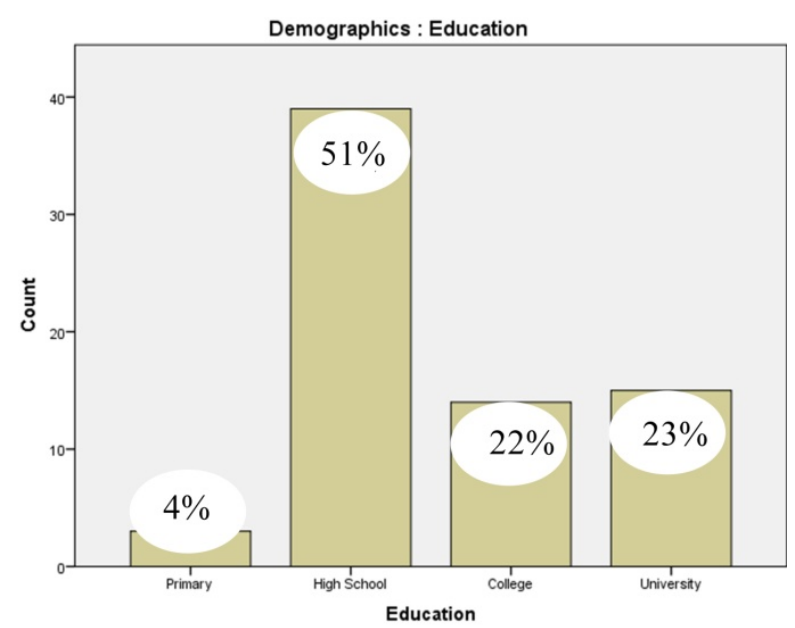

Figure 1. Education demographics of respondents

The results in Figure 2 indicate that the respondents were mostly mature adults and middle aged respondents. This could presumably have assisted the study to have mature and reliable answers.

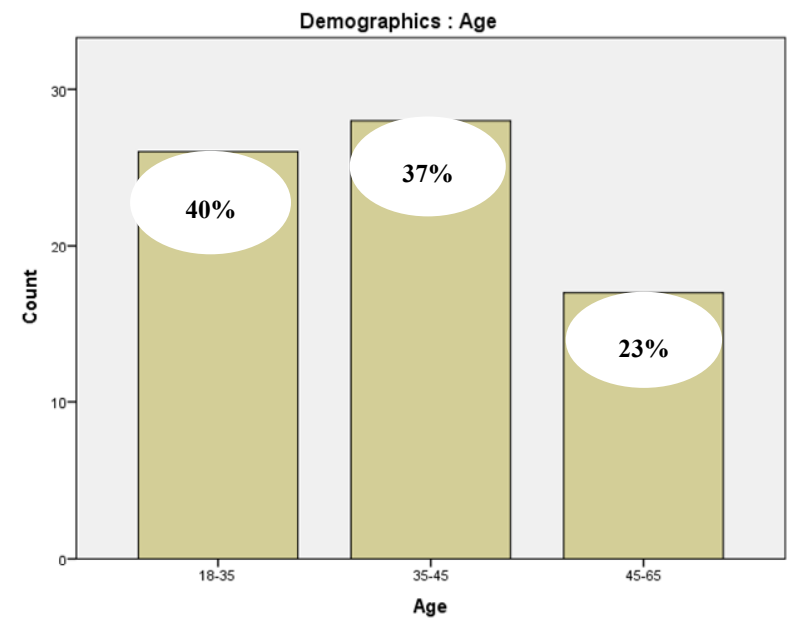

Figure 2. Age demographics of respondents 
The age retirement age group between 45 and 65 years had also a considerable number of respondents of about 16 and these respondents could have assisted in giving informed answers due to the considerable number of years and experience, as well as, their skills. The age group with most respondents was between 35-45, with about 28 respondents, followed by the 18-35 age groups, with about 26 respondents. Lastly, the 45-65 age groups had about 16 respondents.

In order to determine the current state of hazardous waste minimization at the company various "Yes or No" questions were asked in the second section of the questionnaire. This included amongst others questions like, "do you know what hazardous waste is; has the organization implemented any waste minimization strategies?" For the "Yes or No" questions inferential statistics (binomial test) was used. All the p-values proved significant in indicating a significantly larger proportion of "Yes" responses.

As highlighted in Tables 1 and 2, the number of respondents of the two questions is almost the same. From the questionnaires issued, about $95.0 \%$ of the respondents knew what hazardous waste and waste minimization meant. This could however be an indication of that the targeted population had the basic education level to understand the terms and concepts of this study. As indicated in Figure 1, most respondents had at least high school or matric level education.

Table 1. Do you know what waste minimization is? Age cross tabulation

\begin{tabular}{lccccc}
\hline & & \multicolumn{3}{c}{ Age Tabulation } & \\
\cline { 3 - 5 } & & $18-35$ & $35-45$ & $45-65$ & Total \\
\hline Do you know what waste minimization is? & Yes & 25 & 26 & 16 & 67 \\
& No & 1 & 0 & 3 & 4 \\
Total & & 26 & 26 & 19 & 71
\end{tabular}

Table 2. Do you know what hazardous waste is? Age cross tabulation

\begin{tabular}{lccccc}
\hline & & \multicolumn{3}{c}{ Age Tabulation } & \\
\cline { 3 - 5 } & & $18-35$ & $35-45$ & $45-65$ & Total \\
\hline & Yes & 25 & 28 & 17 & 70 \\
Do you know what hazardous waste is? & No & 1 & 0 & 0 & 1 \\
Total & & 26 & 28 & 17 & 71 \\
\hline
\end{tabular}

Figure 3 clearly displays that $91.0 \%$ of the respondents agreed that this company has implemented waste minimization strategies. This data positively supports the results of the site audit conducted by the researcher prior the study, that the company had a mature environmental management system and elaborate procedures thereof. Despite all these set procedures being in place, the question still needed to be answered was; Is the hazardous waste minimization at the company sustainable or practical and whether all processes in the product life cycle were considered in waste minimization? 


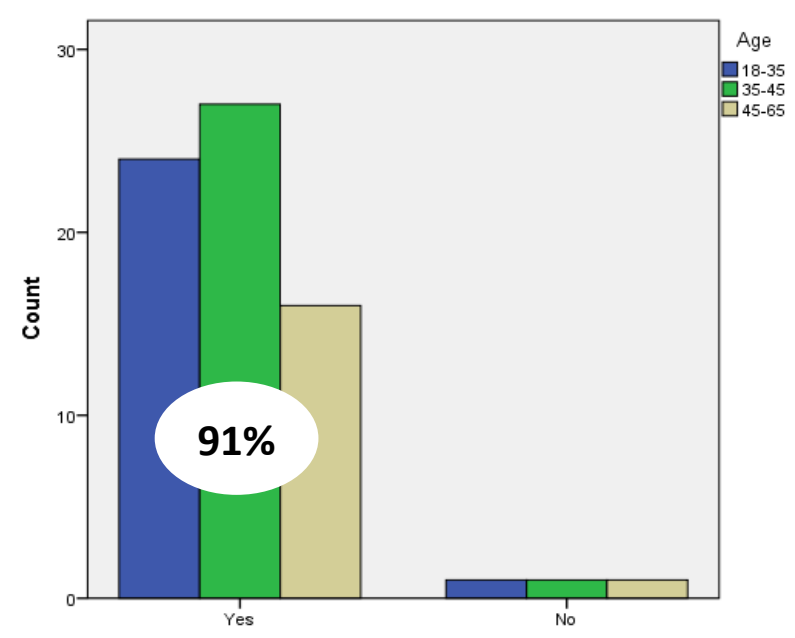

Figure 3. Has the organisation implemented any waste minimization strategies

During literature review and analysis of secondary data it was identified that, one main problem of effective waste minimization lays in the fact that the cost of raw materials and disposal of wastes are underestimated in chemical industries. In consequence, there are usually no economic incentives to develop waste-free processes. This means knowing the cost of hazardous waste production and disposal costs is very crucial. This could also assist in changing employees' behavior towards achieving sustainable hazardous waste minimization at the company (Phillips, 2000).

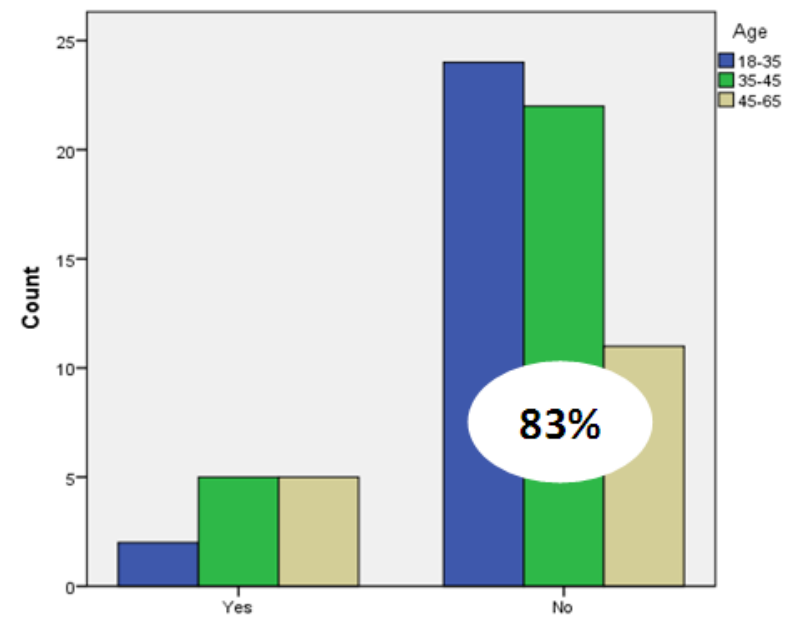

Figure 4. Do you know the average cost of hazardous waste production in your plant per month

Figure 4 exhibits that over half of the employees constituting of almost $83.0 \%$ of the respondents do not know the average cost of hazardous waste production in their respective plants or work station. This highlights one of the short comings in achieving sustainable hazardous waste minimization at the company. In order for organizations to achieve sustainable waste minimization, there is need to identify gaps through various means like surveys, interviews and seek to make improvements.

For any project to be sustainable there is need for public participation. Public participation is one of the key to better sustainable development governance at the international as well as the national level (Bulman, 2011). Sustainable development can be achieved only through the involvement of all stakeholders. The public, being the user of a system, is the only party that can assess and evaluate the impacts of possible measures on the functions of an environment. Public participation and consultation is an opportunity to solicit the "hidden" knowledge of the wider community and their key concerns (Budd, 1999). 
A prior study of the site was undertaken and all the hazardous waste streams at the company were listed. One question in the questionnaires asked the respondents to select or tick hazardous wastes types applicable to their manufacturing plant or work station, from the selected list. To analyse the data of waste types, inferential statistics was also used. The binomial test was used for inferential statistics. Statistically, the binomial test is an exact test of the statistical significance of deviations from a theoretically expected distribution of observations into two categories. By default, the probability parameter for both groups is 0.5 .

Table 3 illustrates the top five selected hazardous waste types applicable to respondents' work stations or plants. Knowing the prevalent hazardous waste streams at an organisation is very important. More focus can be given to the prevalent waste types and thus assisting with minimizing hazardous waste in general.

Table 3. Top five hazardous waste types (Inferential statistics)

\begin{tabular}{|c|c|c|c|c|c|c|}
\hline Waste type & & Category & $\mathrm{N}$ & Observed Proportion & Test Proportion & Exact Significant (2-tailed) \\
\hline \multirow{3}{*}{ Metal/Plastic containers } & Group 1 & Absent & 35 & 0.56 & 0.5 & 0.374 \\
\hline & Group 2 & Present & 27 & 0.44 & & \\
\hline & Total & & 62 & 1 & & \\
\hline \multirow{3}{*}{ Dirty solvent } & Group 1 & Absent & 26 & 0.42 & 0.5 & 0.253 \\
\hline & Group 2 & Present & 36 & 0.58 & & \\
\hline & Total & & 35 & 1 & & \\
\hline \multirow{3}{*}{ Bulk bags } & Group 1 & Absent & 21 & 0.34 & 0.5 & 0.015 \\
\hline & Group 2 & Present & 41 & 0.66 & & \\
\hline & Total & & 62 & 1 & & \\
\hline \multirow{3}{*}{ Sludge } & Group 1 & Absent & 22 & 0.35 & 0.5 & 0.03 \\
\hline & Group 2 & Present & 40 & 0.65 & & \\
\hline & Total & & 62 & 1 & & \\
\hline \multirow{3}{*}{ Waste water } & Group 1 & Absent & 33 & 0.53 & 0.5 & 0.704 \\
\hline & Group 2 & Present & 29 & 0.47 & & \\
\hline & Total & & 62 & 1 & & \\
\hline
\end{tabular}

$-N=$ Number of trials or sample size;

-Observed proportion $=$ Observations in variables;

-Test proportion = statistical method used to test the hypothesis;

-Two-tailed significant tests $=$ are only applicable when there are two tails such as in the normal distribution and correspond to considering either direction significant.

NB: When a statistic is significant, it simply means that you are very sure that the statistic is reliable. It doesn't mean the finding is important or that it has any decision-making utility.

This prevalence can be supported by the $\mathrm{p}$ value as shown in the following two examples:

- Bulk bags $\mathrm{p}=0.015$ with an observed proportion of 0.34 absent and 0.66 present;

- Sludge $\mathrm{p}=0.03$ with an observed proportion of 0.35 absent and 0.65 present. Bulk bag and sludge were the most present waste types; these waste streams had a $\mathrm{p}$ value of less than 0.05 .

The study hypothesized that the lack of sustainable hazardous waste minimization is influenced by certain work place problems. The basis of this assertion is that if these problems are dealt with, then hazardous waste can be minimized more sustainably. The data in Table 4 depicts that the lack of enforcement measure and capability is the main problem with 27 out of 46 people who responded to this question, which is $52.0 \%$ of the respondents having considered this being very serious or serious. This could be the first step that the organization needs to undertake, followed by others respectively in order to totally and sustainably minimize the hazardous waste produced. 
Table 4. Problems that prevents the sustainable minimization of hazardous waste

\begin{tabular}{lcc}
\hline Problems & Very Serious or Serious & Not so Serious or No problem \\
\hline Lack of enforcement measure and capability & $27(59 \%)$ & $19(41 \%)$ \\
Poor response to waste minimization & $25(57 \%)$ & $19(43 \%)$ \\
Lack of financial resources to install new equipment & $23(57 \%)$ & $21(43 \%)$ \\
Lack of equipment & $22(47 \%)$ & $25(53 \%)$ \\
Poor public co-operation & $22(47 \%)$ & $20(53 \%)$ \\
Lack of trained personnel & $21(44 \%)$ & $27(56 \%)$ \\
Lack of control on hazardous waste & $21(54 \%)$ & $19(46 \%)$ \\
Lack of technical information on waste minimization & $20(47 \%)$ & $25(53 \%)$ \\
Technical limitations of production process & $19(45 \%)$ & $23(55 \%)$ \\
Regulatory burdens inhibit recycling & $19(45 \%)$ & $22(55 \%)$ \\
\hline
\end{tabular}

According to the Outdoor Foundation (2012), the life cycle stages are discreet intervals along the life of a finished product and the materials which make up the product where environmental impacts are realized. Every stage of production also poses different environmental impacts. Table 5 illustrates the numbers of respondents who have indicated the product life stages where hazardous waste could be minimized the most. About $50.0 \%$ of the population indicated that raw materials and product manufacturing and assembly stages of the product life cycle are the ones that require greater attention in terms of hazardous waste minimization

As everyone's attention is directed towards the chemical industry, nowadays, a way of monitoring the environmental impact of its processes and products is needed. The assumption of the study is therefore that there are some processes that result to the production of more hazardous waste than the others.

Table 5. Hazardous waste minimization at specific product life cycle stage (descriptive)

\begin{tabular}{lcc}
\hline Product Life cycle stage & Indicated & Not Indicated \\
\hline Materials & $50 \%$ & $50 \%$ \\
Product Manufacturing and Assembly & $45 \%$ & $55 \%$ \\
Packaging & $35 \%$ & $65 \%$ \\
Transport and Distribution & $33 \%$ & $67 \%$ \\
End of Life & $26 \%$ & $74 \%$ \\
Use and Service & $15 \%$ & $85 \%$ \\
\hline
\end{tabular}

Bearing the importance of processes in mind, the researcher identified the processes in the manufacturing company within study. The purpose of identifying these processes was to determine the severe processes that lead to the production of hazardous waste. The top ten severe processes are displayed in Figure 5. Amongst the ten processes, eight of them were related to raw materials processes. This calls for attention to concentrate on raw materials processes in order for hazardous waste to be minimized sustainable. 


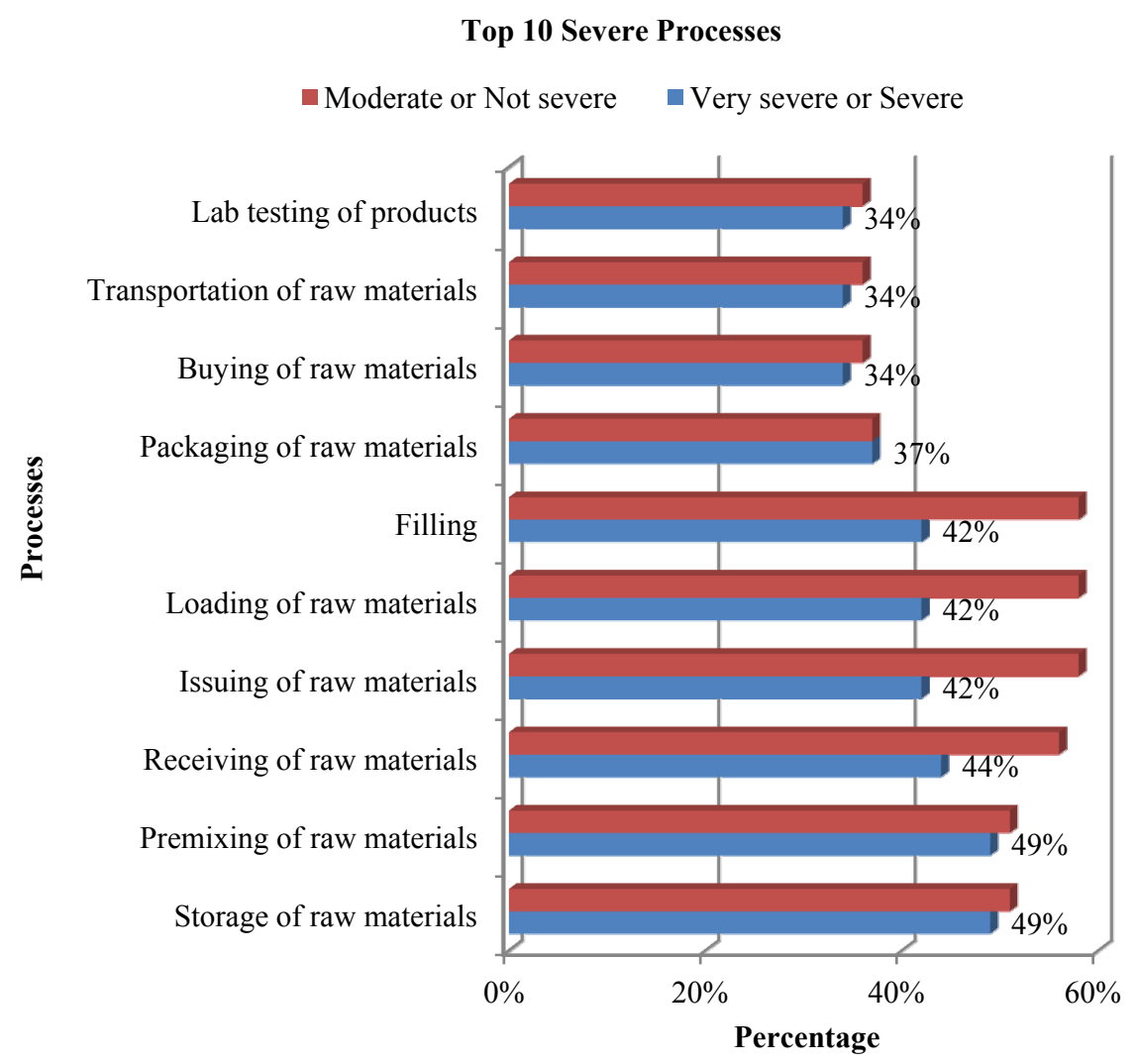

Figure 5. Top 10 severe processes that produce hazardous waste

\section{Summary and Conclusion}

With the assistance of the questionnaire survey, an analysis of the six stages of the product life cycle and manufacturing processes were undertaken. The paper identified the product life cycle stage or the processes that produced much hazardous waste, with the purpose of identifying prevalent areas of focus. Among other processes and product life cycle stages, the management of raw materials was found to be predominant in the results. In order to minimize hazardous waste, manufacturing companies need to consider proper planning in buying raw materials, issuing, and storage thus avoiding any redundancy of raw materials.

This paper succeeded in highlighting challenges of achieving hazardous waste minimization in chemical industries locally and globally. The analysis of the results suggest that there is a considerable room for improvement for a sustainable hazardous waste minimization environment or work place by ascertaining that employees are made aware and trained thoroughly on the issues of hazardous waste.

One objective of the study was to determine the amount and severity of waste generated which helps to facilitate effective waste management decision-making during the response. From the results of the waste type questions in the questionnaire, bulk bags, dirty solvents, metal or plastic containers, sludge and waste water were found to be on the top five (5) amongst other waste streams in terms of amount produced and severity. Knowledge on amount of waste types generated affects decisions regarding how to manage the waste, including the storage, treatment, and disposal of the waste. This study hypothesized that there are some specific causes and problems that inhibit individuals or organization to minimize hazardous waste sustainable. Human development in terms of motivation and training was found to be very crucial. Organizations need to therefore enforce, regulate and maintain sustainable strategies towards hazardous waste minimization.

An investigation of the recycling companies in South Africa was undertaken to verify if many of them have started to recycle end products of some industries. In paint manufacturing industries for example, this could be the reusing or recycling of for example filter cake which is an end product in paint manufacturing. All the recyclers contacted were found to be not involved in such activities. Rather, common recyclables like paper, plastic and wood were the one that were being recycled. This study also discovered that cradle to cradle is more 
practical in developed countries were the technology is more advanced. In order to assist African countries in effective waste minimization, future researchers may assess the encroaching of cradle to cradle approach and how African countries can advance successfully from cradle to grave to the cradle to cradle approach.

\section{References}

Budd, M. (1999). The application of environmental assessment to marine development and activities in Great Britain. Marine Policy, 23(4-5), 439-451. http://dx.doi.org/10.1016/S0308-597X(98)00050-5

Bulman, R. (2011). Public participation. Retrieved on August 8, 2013, from $\mathrm{http} / /$ www.custodianproject.co.za/index.php?option $=\mathrm{com} \_\mathrm{k} 2 \& \mathrm{view}=$ itemlist\&task=category\&id=6:publicparticipation\&Itemid $=72$

Carroll-Foster, T. (1993). A Guide to Agenda 21: Issues, Debates and Canadian Initiatives, Ottawa: The International Development Research Centre.

DEA (Department of Environmental Affairs). (2010). National Waste Management Strategy. Retrieved on September 21, 2012 from http://www.wastepolicy.co.za/nwms/

Fehr, E., \& Schmidt, K. M. (1999). A Theory Of Fairness, Competition, And Cooperation. The Quarterly Journal of Economics, 114(3), 817-868. http://dx.doi.org/10.1162/003355399556151

Hatlar Group. (2009). Waste hierarchy. Retrieved from http://www.hatlar.com/index.php?action=help\&helpcatID=303\&helpID=1716\#1716

Jennings, L. (2010). A once off greenstay project on "Waste Chemicals and Management. Retrieved on September 21, 2012, from http://www.greenstaysa.org.za

Laerd. (2013). Descriptive and Inferential Statistics. Retrieved on August 8, 2012, from https://statistic s.laerd.com/statistical-guides/descriptive-inferential-statistics.php

Out Door Foundation. (2012). Lifecycle Stages. Retrieved on March 21, 2013, from http://www.outdoorindustry.org/responsibility/resources/lifecycle.html

Phillips, P. S. (2000). Guide for waste minimization.UK Lecture material. UK: University of College Northampton.

Sheldon, C., \& Yoxon, M. (2006). Environmental Management Systems: A step-by-step guide to implementation \& maintenance. London: Earthscan.

\section{Copyrights}

Copyright for this article is retained by the author(s), with first publication rights granted to the journal.

This is an open-access article distributed under the terms and conditions of the Creative Commons Attribution license (http://creativecommons.org/licenses/by/3.0/). 